\title{
Design of the main racetrack microtron accelerator end magnets of the Institute of Physics of University of São Paulo
}

\author{
L. R. P. Kassab \\ Faculty of Technology, Centro Estadual de Educação Tecnológica "Paula Souza”-UNESP, São Paulo, SP, Brazil \\ Praça Coronel Fernando Prestes 30, CEP 01124-060, São Paulo, SP, Brazil \\ M. N. Martins, J. Takahashi, and P. Gouffon \\ Institute of Physics, University of São Paulo, São Paulo, Brazil
}

(Received 16 November 1998; published 11 March 1999)

\begin{abstract}
This work deals with the design of the Institute of Physics of the University of São Paulo (IFUSP) main racetrack microtron accelerator end magnets. This is the last stage of acceleration, comprised of an accelerating section $(1.04 \mathrm{~m})$ and two end magnets $(0.1585 \mathrm{~T})$, in which a $5.10 \mathrm{MeV}$ beam, produced by a racetrack microtron booster has its energy raised up to $31.15 \mathrm{MeV}$ after 28 accelerations. POISSON code was used to give the final configuration that includes auxiliary pole pieces (clamps) and auxiliary homogenizing gaps. The clamps create a reverse fringe field region and avoid the vertical defocusing and the horizontal displacement of the beam produced by extended fringe fields; PTRACE code was used to perform the trajectory calculations in the fringe field region. The auxiliary homogenizing gaps improve the field uniformity as they create a "magnetic shower" that provides uniformity of $\pm 0.3 \%$, before the introduction of the correcting coils that will be attached to the pole faces. This method of correction, used in the IFUSP racetrack microtron booster magnets, enabled uniformity of $\pm 0.001 \%$ in an average field of $0.1 \mathrm{~T}$ and will also be employed for these end magnets. [S1098-4402(99)00031-2]
\end{abstract}

PACS numbers: 41.85.Lc

\section{INTRODUCTION}

We present the design of the Institute of Physics of the University of São Paulo (IFUSP) main racetrack microtron accelerator end magnets [1]. The machine operation is based on the resonance condition [2] $2 \pi \Delta E / q B c^{2}=\nu T_{\mathrm{RF}}(\Delta E$ is the energy gain, $B$ is the magnetic field, $c$ is the velocity of the light in the vacuum, and $\nu$ is the multiple integer of the radio frequency period $T_{\mathrm{RF}}$ ) that determines, in first order, the magnetic field. This condition assumes that the magnetic field is uniform and, at the magnet edge, falls to zero abruptly (hard edge field). So these field requirements for the machine operation must be considered in the design of the end magnets whose field distributions have to enable the establishment of trajectories that are very near to the ideal ones. The end magnets incorporate homogenizing air gaps and auxiliary pole pieces that were designed with the aid of POISSON. We should remark that, for the microtron booster end magnets [3], the calculations done with POISSON presented good agreement with the measurements. We also present the trajectory calculations, performed with PTRACE code, in which the effects of the extended fringe field (EFF) [4] are compared with those of the reverse fringe field.

\section{THE DESIGN OF THE END MAGNETS}

The fundamental problem in end magnet design is to achieve high field uniformity, in an economical way, for a large ratio of gap depth to height. Two configurations are appropriate: the $\mathrm{C}$ magnet and the half-picture-frame
(HPF) magnet. The HPF configuration, although more economic in iron, is limited in field uniformity. This is manifested by the significant angle of the field lines with the perpendicular direction to the pole face in the iron-air interface and this can be seen by comparing the field lines of the different profiles that were simulated using POISSON, a two-dimensional program [Figs. 1(a) and 1(b)]. So, for the end magnets of the main racetrack microtron, we decided to use the $\mathrm{C}$ configuration. All the profiles that will be discussed incorporate auxiliary pole pieces that avoid the effects caused by extended fringe field that affect the trajectories and, consequently, the synchronism between the accelerating microwave and the beam. The preliminary calculations with a HPF configuration [Fig. 1(a)] revealed that, to attain uniformity of $\pm 0.8 \%$ (Fig. 2, magnet 1) in the middle plane, in an average field of $0.1585 \mathrm{~T}$, the height of the magnets would be $120 \mathrm{~cm}$ and this would not represent an economical solution. Besides, the coils would occupy part of the gap. For the $\mathrm{C}$ configuration [Fig. 1(b)], there would be variations of $\pm 0.4 \%$ (Fig. 2, magnet 2) for almost the same mass of iron.

A more economical solution was found for a $\mathrm{C}$ configuration with height reduced 50\% [Fig. 1(c)], when compared to the profiles of Figs. 1(a) and 1(b), but with field variations of $\pm 0.9 \%$ (Fig. 2, magnet 3 ) in the middle plane. In these three cases we observe that the field decreases as it approaches the edge of the magnet. This is caused by the trajectory of the field lines in the iron region. The best solution was found with the $\mathrm{C}$ configuration shown in Fig. 1(c) with the homogenizing air gap, $1 \mathrm{~cm}$, between the pole pieces and the yoke [Fig. 1(d)], 

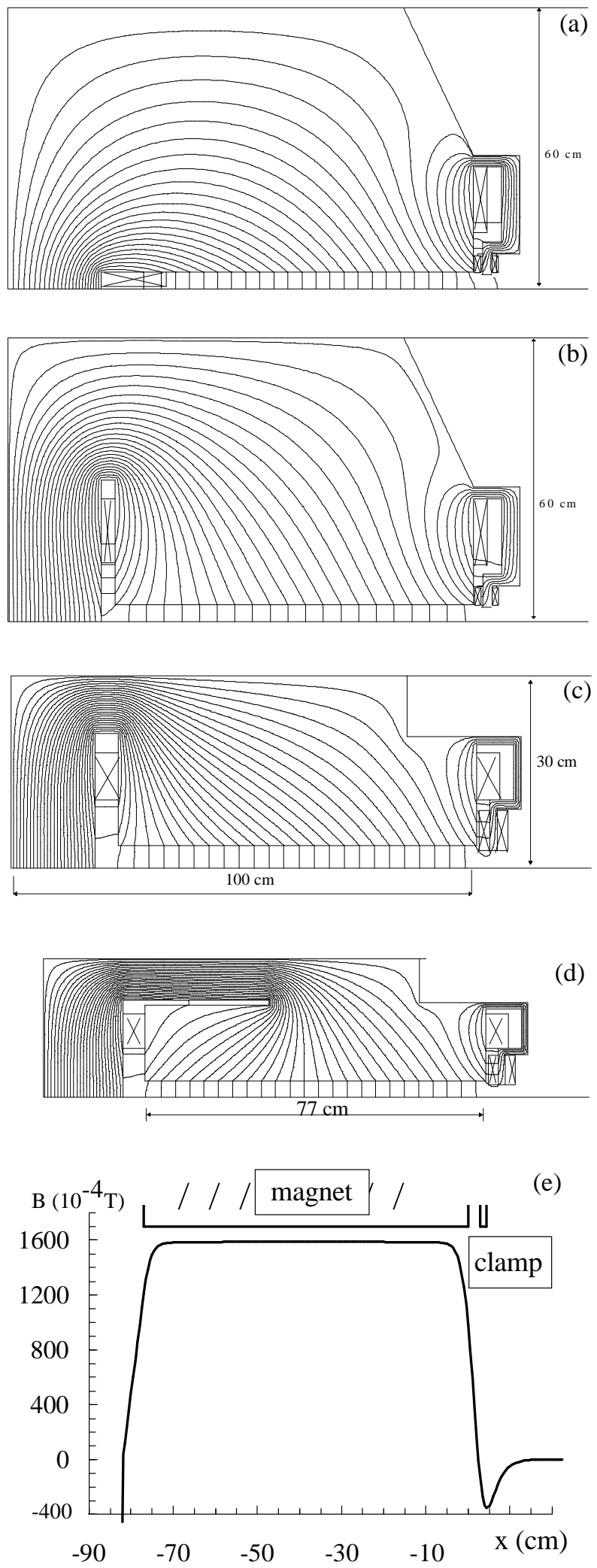

FIG. 1. The design of a racetrack microtron end magnet: (a) HPF configuration (magnet 1), (b) high $\mathrm{C}$ configuration (magnet 2), (c) low $\mathrm{C}$ configuration (magnet 3), and (d) low $\mathrm{C}$ configuration with homogenizing air gaps of $1 \mathrm{~cm}$ (magnet 4) and the magnetic field distribution in the middle plane, as a function of distance to the pole edge.

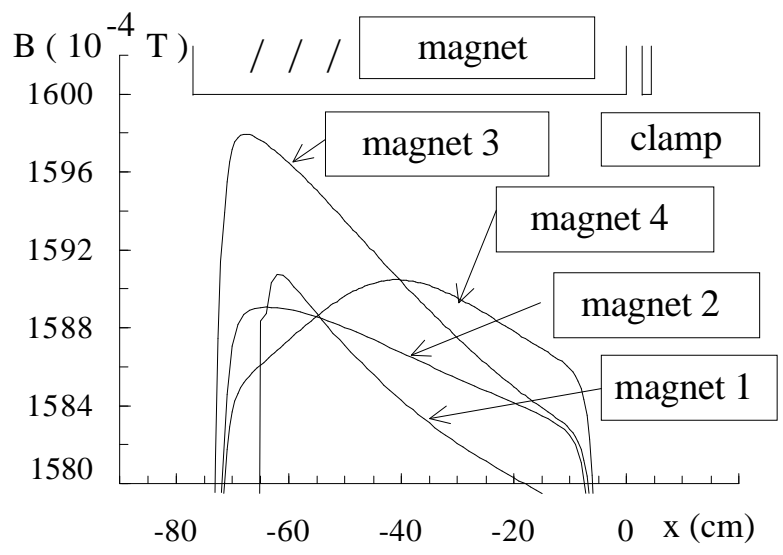

FIG. 2. Magnetic field distributions, in the middle plane, calculated with POISSON for the configurations shown in Fig. 1.

that provides uniformity of $\pm 0.3 \%$ (Fig. 2, magnet 4 ) in the middle plane. This design is discussed below.

The area of the pole pieces depends on the radius of the last orbit $(66.6 \mathrm{~cm})$. The end magnets were designed with height of $60 \mathrm{~cm}$, rectangular pole pieces with $77 \times$ $170 \mathrm{~cm}^{2}$, gap height of $7 \mathrm{~cm}$, homogenizing air gaps of $1 \mathrm{~cm}$, and weight of $7 \times 10^{4} \mathrm{~N}$. The position and the height of the homogenizing gaps were determined with POISSON code. These homogenizing gaps differ from the Purcell filters, that are usually inserted near the main gap, and enable an economical solution because they deviate the field lines and create a "magnetic shower" (name given because of the field lines shape), improving the field uniformity. So they avoid the decrease of the magnetic field, as it happens to the other three profiles exposed. We should remark that the field uniformity will be optimized by the method of correction used in the racetrack microtron booster end magnets, that provided uniformity [5-7] of $\pm 0.001 \%$, in an average field of $0.1 \mathrm{~T}$, even when the current of operation was varied $[8,9]$ up to $\pm 10 \%$. This method of correction is based on attaching to the pole faces correcting coils made of etched printed circuits whose copper leads are shaped like the isofield lines of the uncorrected magnet. Table I presents the parameters of the main racetrack

TABLE I. Parameters of the main racetrack microtron.

\begin{tabular}{lc}
\hline \hline Injection energy $(\mathrm{MeV})$ & 5.10 \\
Output energy $(\mathrm{MeV})$ & 31.15 \\
Accelerating microwave $(\mathrm{cm})$ & 12.24 \\
Energy gain per turn $(\mathrm{MeV})$ & 0.93 \\
Total number of orbits & 29 \\
Radius of the first orbit $(\mathrm{cm})$ & 11.46 \\
Radius of the last orbit $(\mathrm{cm})$ & 66.57 \\
Magnetic field $(\mathrm{T})$ & 0.1585 \\
Average bean current $(\mu \mathrm{A})$ & 50 \\
Distance between magnets $(\mathrm{cm})$ & 199.8 \\
\hline \hline
\end{tabular}


TABLE II. Characteristics of the four configurations.

\begin{tabular}{lccc}
\hline \hline \multicolumn{1}{c}{ Configuration } & $\begin{array}{c}\text { Mass } \\
(\mathrm{kg})\end{array}$ & $\begin{array}{c}\text { Total current } \\
(\mathrm{A} \times \text { turns })\end{array}$ & $\begin{array}{c}\Delta B / B \\
(\%)\end{array}$ \\
\hline HPF & 15200 & 4480 & 0.8 \\
High C & 15000 & 4570 & 0.4 \\
Low C & 7100 & 4730 & 0.9 \\
Low C with & & & \\
$\quad$ homogenizing gaps & 7000 & 5030 & 0.3 \\
\hline \hline
\end{tabular}

microtron of IFUSP. Table II shows some characteristics of the four configurations discussed in this work.

The end magnets also incorporate auxiliary pole pieces (active clamps), with opposite excitation to that of the main poles, that provide a reverse fringe field region [Fig. 1(d)]. These clamps avoid the effects caused by EFF that compromise the machine operation: vertical defocusing and horizontal displacement of the beam. So, the reverse fringe field [10], as will be shown, avoids the vertical defocusing and reduces the horizontal displacement. This was corroborated with PTRACE code that does numerical integration in the reverse fringe field region and calculates the trajectory and the energy of each orbit. We should add that the end magnets will be mounted from pieces of laminated iron, in order to avoid Foucault currents that affect the magnet's performance because they deteriorate the homogeneity and the reproducibility of the magnetic field [11].

Table III presents the coil parameters of the end magnets. The main coils will be constructed with copper wire of $7.010 \mathrm{~mm}$ diameter arranged in seven layers of 11 turns each. The power dissipated in each coil is about $107 \mathrm{~W}$ when submitted to a 65.32 A current, necessary to generate a magnetic field of $0.1585 \mathrm{~T}$. Each auxiliary coil, made with copper wire of $2.032 \mathrm{~mm}$ diameter, disposed in 12 layers of 31 turns, dissipates approximately $11 \mathrm{~W}$ when submitted to $4.4 \mathrm{~A}$.

\section{TRAJECTORY CALCULATIONS}

The trajectory calculations show the effect of the reverse fringe field in the middle plane and in the ones situated out of it. Figure 3 shows the trajectories of the first and last orbits, in the middle plane, in the presence of the extended and the reverse fringe fields in which we

TABLE III. Coil parameters.

\begin{tabular}{lcc}
\hline \hline & Main coil & Auxiliary coil \\
\hline Wire diameter $(\mathrm{mm})$ & 7.010 & 2.032 \\
Number of turns & 77 & 372 \\
Total current $(\mathrm{A} \times$ turns) & 5030 & 1640 \\
Current $(\mathrm{A})$ & 65.32 & 4.4 \\
Resistance $(\mathrm{m} \Omega)$ & 25.15 & 581.6 \\
\hline \hline
\end{tabular}

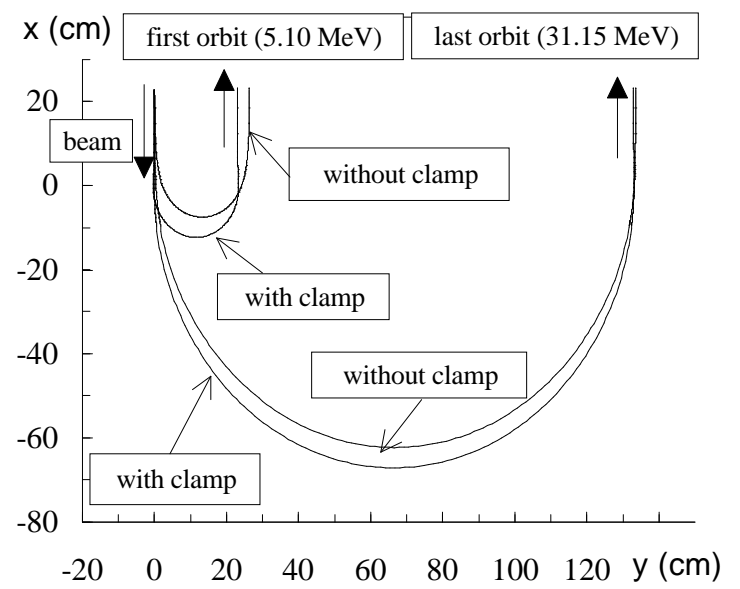

FIG. 3. Trajectories in the presence of the extended fringe field (without clamp) and the reverse fringe field (with clamp), in the middle plane.

observe beam displacements that are more significant for lower energies $(3.36 \mathrm{~cm}$ for the first orbit and $0.52 \mathrm{~cm}$ for the last one).

Figures 4, 5, and 6 exhibit calculations for a particle that comes into the field $0.1 \mathrm{~cm}$ above the middle plane. In the EFF case, vertical displacements of $2 \mathrm{~mm}$, for the first orbit, and of $0.2 \mathrm{~mm}$, for the last one, are observed (Fig. 4). For the reverse fringe field, these vertical displacements are of $40 \mu \mathrm{m}$ for the first orbit (Fig. 5) and of $4 \mu \mathrm{m}$ for the last one (Fig. 6). Table IV presents the radius and the energy of some of the main racetrack microtron orbits calculated with PTRACE code.

\section{CONCLUSION}

The simulations performed with POISSON and PTRACE codes show that the field distribution of the end magnets

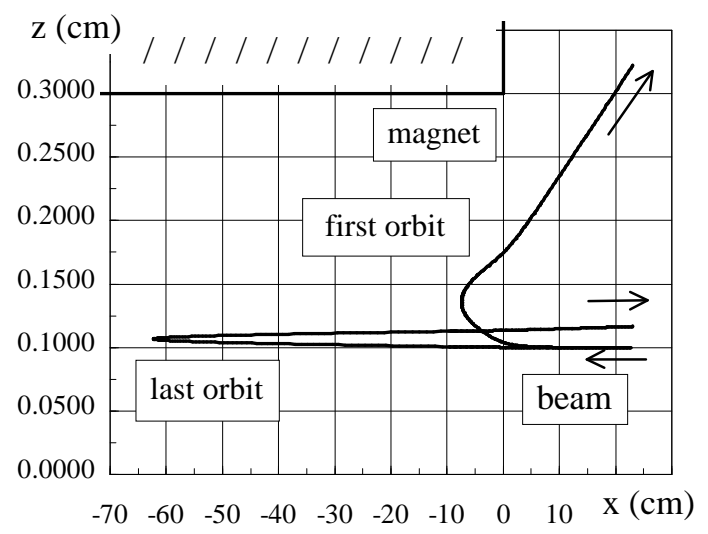

FIG. 4. Trajectories of the first and the last orbits of a particle coming into the extended fringe field $0.1 \mathrm{~cm}$ above the middle plane. 


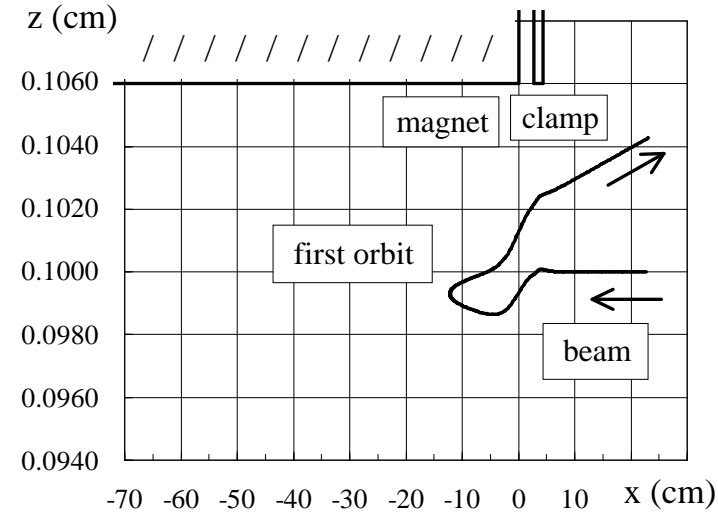

FIG. 5. First orbit trajectory of a particle coming into the reverse fringe field $0.1 \mathrm{~cm}$ above the middle plane.

fulfills the requirements for the machine operation. The introduction of homogenizing air gaps improved the uniformity of the magnetic field from $\pm 0.9 \%$ to $\pm 0.3 \%$. We should remark that there will probably appear inhomogeneities coming from material and mechanical problems. The introduction of correcting coils will then eliminate these problems. The active clamps were incorporated to avoid the effects caused by extended fringe fields. The horizontal displacements are reduced in about $3 \mathrm{~cm}$, for the worst case. For the vertical movement, we observe maximum displacements of $40 \mu \mathrm{m}$, that is to say, weak vertical defocusing forces that maintain the trajectories very close to the middle plane.

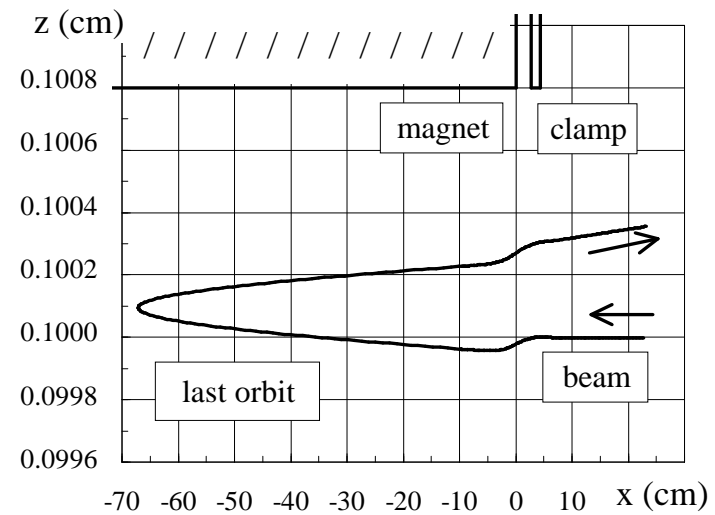

FIG. 6. Last orbit trajectory of a particle coming into the reverse fringe field $0.1 \mathrm{~cm}$ above the middle plane.
TABLE IV. Radius and energy of the orbits calculated with PTRACE.

\begin{tabular}{ccr}
\hline \hline Orbit & $\begin{array}{c}\text { Radius } \\
(\mathrm{cm})\end{array}$ & $\begin{array}{r}\text { Energy } \\
(\mathrm{MeV})\end{array}$ \\
\hline 1 & 11.46 & 5.10 \\
5 & 19.53 & 8.87 \\
10 & 29.38 & 13.51 \\
15 & 39.18 & 18.16 \\
20 & 48.99 & 22.81 \\
25 & 58.78 & 27.45 \\
29 & 66.57 & 31.15 \\
\hline \hline
\end{tabular}

\section{ACKNOWLEDGMENTS}

We express our thanks to FATEC-SP for its encouragement during this work and to João A. de Lima, responsible for the construction of the racetrack microtron booster end magnets in IFUSP, who gave suggestions concerning the mechanical problems of the main racetrack microtron end magnets design. We also thank FAPESP for support.

[1] L. R. P. Kassab, J. Takahashi, M. N. Martins, and P. Gouffon, in Proceedings of the Sixth European Particle Accelerator Conference, Stockholm, 1998, edited by S. Myers et al. (Institute of Physics Publishing, Bristol, 1998), p. 1937.

[2] R. E. Rand, in Recirculating Electron Accelerators (Harwood Academic Publishers, New York, 1984).

[3] L. R. P. Kassab, P. Gouffon, M. N. Martins, and J. Takahashi, Part. Accel. 59, 75 (1998).

[4] H. A. Enge, Rev. Sci. Instrum. 35, 278 (1964).

[5] L. R.P. Kassab, P. Gouffon, and M.N. Martins, Nucl. Instrum. Methods Phys. Res., Sect. A 404, 181 (1998).

[6] L. R. P. Kassab, thesis, Instituto de Física da Universidade de São Paulo, 1996.

[7] L. R. P. Kassab, P. Gouffon, and M. N. Martins, Part. Accel. (to be published).

[8] L. R.P. Kassab and P. Gouffon, in Proceedings of the 1997 Particle Accelerator Conference, Vancouver, Canada, 1997, edited by M. Comyn, M. K. Craddock, M. Reiser, and J. Thomson (IEEE, Piscataway, NJ, 1998), p. 3239.

[9] L. R. P. Kassab and P. Gouffon, Phys. Rev. ST Accel. Beams 1, 012401 (1998).

[10] H. Babic and M. Sedlacek, Nucl. Instrum. Methods 56, 170 (1976).

[11] K. Halbach, Nucl. Instrum. Methods 107, 529 (1972). 